\title{
Analysis of the Release Characteristics of Cu-Treated Antimicrobial Implant Surfaces Using Atomic Absorption Spectrometry
}

\author{
Carmen Zietz, ${ }^{1}$ Andreas Fritsche, ${ }^{1}$ Birgit Finke, ${ }^{2}$ Vitezslav Stranak, ${ }^{3}$ Maximilian Haenle, ${ }^{1}$ \\ Rainer Hippler, ${ }^{3}$ Wolfram Mittelmeier, ${ }^{1}$ and Rainer Bader ${ }^{1}$ \\ ${ }^{1}$ Biomechanics and Implant Technology Research Laboratory, Department of Orhtopeadics, University of Rostock, \\ Doberaner Straße 142, 18057 Rostock, Germany \\ ${ }^{2}$ Leibniz Institute for Plasma Science and Technology (INP e.V. Greifswald), Felix-Hausdorff-Straße 2, 17489 Greifswald, Germany \\ ${ }^{3}$ Institute of Physics, Ernst-Moritz-Arndt University of Greifswald, Felix-Hausdorff-Straße 6, 17487 Greifswald, Germany
}

Correspondence should be addressed to Carmen Zietz, carmen.zietz@med.uni-rostock.de

Received 1 September 2011; Accepted 24 October 2011

Academic Editor: Reinhard Paschke

Copyright ( 2012 Carmen Zietz et al. This is an open access article distributed under the Creative Commons Attribution License, which permits unrestricted use, distribution, and reproduction in any medium, provided the original work is properly cited.

\begin{abstract}
New developments of antimicrobial implant surfaces doped with copper $(\mathrm{Cu})$ ions may minimize the risk of implant-associated infections. However, experimental evaluation of the $\mathrm{Cu}$ release is influenced by various test parameters. The aim of our study was to evaluate the $\mathrm{Cu}$ release characteristics in vitro according to the storage fluid and surface roughness. Plasma immersion ion implantation of $\mathrm{Cu}(\mathrm{Cu}-\mathrm{PIII})$ and pulsed magnetron sputtering process of a titanium copper film (Ti-Cu) were applied to titanium alloy (Ti6Al4V) samples with different surface finishing of the implant material (polished, hydroxyapatite and corundum blasted). The samples were submersed into either double-distilled water, human serum, or cell culture medium. Subsequently, the $\mathrm{Cu}$ concentration in the supernatant was measured using atomic absorption spectrometry. The test fluid as well as the surface roughness can alter the $\mathrm{Cu}$ release significantly, whereby the highest $\mathrm{Cu}$ release was determined for samples with corundum-blasted surfaces stored in cell medium.
\end{abstract}

\section{Introduction}

Total joint replacement (TJR) meets high quality and safety standards and has become a frequent surgical procedure in order to restore joint function [1]. However, implant revision remains a relevant problem in clinical use. Failure of TJR is mainly due to aseptic loosening caused by inflammatory reactions due to wear particles [2]. Postoperative implantassociated infections are rare but considered devastating complications after TJR. Although surgical techniques and environmental conditions during the surgical intervention have improved over the years, infections occur with a frequency of $0.5-2 \%$ with incisive consequences for the patients and medical costs [3]. Most implant-associated infections are caused by Staphylococcus aureus and Staphylococcus epidermidis $[4,5]$.

Immediately after implantation bacteria, and human host cells compete for the implant surface in the so-called "race for the surface" [6]. If bacteria adhere to the implant surface prior to human bone cells, biofilm formation might occur and osseous integration of the implant is precarious. In terms of biofilms, the treatment of implant-associated infections can be further hindered by the thus increased bacterial resistance against antibiotics [7]. Novel developments of ionbased antimicrobial implant surfaces such as silver $(\mathrm{Ag})$ [8] or copper $(\mathrm{Cu})$ [9] might offer a possible solution to this problem. Various in vitro and in vivo studies confirm the antibacterial properties and cytocompatibility of $\mathrm{Cu}$ [10-13]. Other alternative antibacterial materials and agents are in development or already in use to prevent or treat implantassociated infections [14-18]. In vitro investigations of the antibacterial effects are usually performed on simplified samples and under simplified testing conditions, whereas in vivo tests are usually closer to the final application. In vitro conditions are often adjusted according to the respective test, that is, cell biological and microbiological tests are performed 
with regard to their specific test protocols. Test fluids, storage times and fluid volume are essential parameters to characterise the antibacterial behaviour as well as the cytocompatibility and release kinetics of the antibacterial agents. Furthermore, the surface characteristics, such as the surface roughness, are an important aspect for coated surfaces with regard to the ion release properties [19]. Moreover, the ion release of ion-based antimicrobial coatings is of essential interest for the bactericidal activity and the cyto-compatibility of the coating.

The aim of the present study was to evaluate the $\mathrm{Cu}$ release characteristics of two different plasma surface treatments doped with $\mathrm{Cu}$ according to the storage fluid and surface roughness of the samples in order to provide an approach for possible standardised investigations in the future.

\section{Materials and Methods}

Titanium alloy (Ti6Al4V) discs (11 $\mathrm{mm}$ in diameter, $2 \mathrm{~mm}$ in height) were used as specimens for the investigation of ion release characteristics of $\mathrm{Cu}$-doped plasma implant treatments. Two different plasma processes applying $\mathrm{Cu}$ were used: a plasma immersion ion implantation process $(\mathrm{Cu}-$ PIII) [20] and a pulsed magnetron sputtering process of a Ti-Cu film [21].

To analyse the influence of the composition of the test fluid on the $\mathrm{Cu}$ release, the $\mathrm{Cu}-\mathrm{PIII}$, and $\mathrm{Ti}$-Cu-coated test samples were placed in 24-well plates and covered with $700 \mu \mathrm{L}$ test fluid. Additionally, uncoated Ti6Al4V test samples were submersed as a reference. The following test fluids were used: double-distilled water (TKA Wasseraufbereitungssysteme $\mathrm{GmbH}$, Niederelbert, Germany), human serum (invitrogen, Darmstadt, Germany), and Dulbecco's Modified Eagle's medium (DMEM, Invitrogen, Carlsbad, USA) with $10 \%$ fetal calf serum (FCS Gold, PAA Laboratories $\mathrm{GmbH}$, Pasching, Austria) as well as 1\% gentamicin (Ratiopharm GmbH, Ulm, Germany). Subsequently, the samples were incubated at $37^{\circ} \mathrm{C}$ in a humidified atmosphere with $5 \% \mathrm{CO}_{2}$ for $24 \mathrm{~h}$ to simulate physiological conditions. All samples were corundum-blasted before plasma treating and exhibited a surface roughness after plasma treatment of $\mathrm{Ra}$ $=3.76 \pm 0.7 \mu \mathrm{m}$ and $2.02 \pm 0.1 \mu \mathrm{m}$ for the Cu-PIII and Ti$\mathrm{Cu}$ coatings, respectively. Three samples of each coating were submersed for each test fluid configuration.

In addition, to evaluate a possible influence on the $\mathrm{Cu}$ release due to surface topology and roughness, three different surface treatments of the Ti6Al4V samples were performed before Cu-PIII plasma treatment: polishing $(\mathrm{Ra}=0.09 \pm$ $0.09 \mu \mathrm{m})$, hydroxyapatite (HA) blasting $(\mathrm{Ra}=1.17 \pm 0.2 \mu \mathrm{m})$, and corundum blasting $(\mathrm{Ra}=4.44 \pm 0.5 \mu \mathrm{m})$. Subsequently three $\mathrm{Cu}$-PIII treated samples of each surface roughness, were immersed in double-distilled water for 5 days. Furthermore, roughness was investigated after storage in DMEM for 24 hours.

After the lapse of submersion time, the supernatants were removed from the samples and $1 \%$ nitric acid $\left(\mathrm{HNO}_{3}\right)$ was added to stabilize the released $\mathrm{Cu}$ ions. In addition, the supernatants were diluted for the following atomic absorption spectrometry (AAS) analysis. By means of an AAS with electrothermal atomization (ZEEnit 650, Analytik Jena AG, Jena, Germany), the concentration of $\mathrm{Cu}$ ions released into the supernatants from the $\mathrm{Cu}$ plasma treatments was determined.

Thereby, the solutions of the different samples were evaporated in a three-step process $\left(90^{\circ} \mathrm{C}\right.$ for $20 \mathrm{~s}, 105^{\circ} \mathrm{C}$ for $20 \mathrm{~s}, 110^{\circ} \mathrm{C}$ for $10 \mathrm{~s}$ ) followed by a pyrolysis phase at $850^{\circ} \mathrm{C}$ $(10 \mathrm{~s})$ in a platform tube. The pyrolysis phase eliminates residual organic material and combusts solid particles from the solution into ash. Using a rapid heat increase $\left(1500^{\circ} \mathrm{C} / \mathrm{s}\right)$, the tube was heated to $2000^{\circ} \mathrm{C}$ for $4 \mathrm{~s}$ to vaporize and convert solid particles into free atoms. This step also included the element analysis using a hollow cathode lamp with a $\mathrm{Cu}$ cathode radiating at $324.8 \mathrm{~nm}$. Parts of the total emitted intensity were absorbed by the $\mathrm{Cu}$ atoms present in the tube from the diluted solution samples of the release experiments. The measured intensity was compared with the intensity of a standard $\mathrm{Cu}$ reference allowing the determination of the $\mathrm{Cu}$ concentration in the supernatants. In a final step the platform tube was cleaned by heating up to $2300^{\circ} \mathrm{C}$ for $4 \mathrm{~s}$.

All data were stored and analyzed using the SPSS statistical package 15.0 (SPSS Inc. Chicago, Ill, USA). Descriptive statistics were computed for continuous and categorical variables [22]. The statistical data included mean and standard deviations of continuous variables, frequencies, and relative frequencies of categorical factors. Comparisons within the independent groups were achieved using the ANOVA test (Post Hoc LSD). All $P$ values resulted from twosided statistical tests, and values of $P<0.05$ were considered to be significant.

\section{Results}

The uncoated Ti6Al4V control test samples showed no traces of copper in the supernatant. However, specific release characteristics were found for the analysed $\mathrm{Cu}$-doped Ti6Al4V samples in different supernatants (Figure 1). Hereby, DMEM provoked the highest $\mathrm{Cu}$ ion release with a significant increase compared to double-distilled water $(P \leq 0.001)$, but no statistical significance was observed when compared to human serum $(P \geq 0.068)$. Higher $\mathrm{Cu}$ concentrations were released from the Ti-Cu films than from the $\mathrm{Cu}$-PIII-treated surfaces in human serum $(4.96 \pm 0.22 \mathrm{mmol} / \mathrm{l}$ versus $1.25 \pm$ $0.01 \mathrm{mmol} / \mathrm{l})$ and in DMEM $(5.27 \pm 0.90 \mathrm{mmol} / \mathrm{l}$ versus 2.00 $\pm 0.63 \mathrm{mmol} / \mathrm{l})$, respectively. Using double-distilled water, the observed concentration of released $\mathrm{Cu}$ was significantly lower $(P \leq 0.019)$ compared to human serum and DMEM and approximately the same for all samples with different $\mathrm{Cu}$ treatments (Ti-Cu: $0.20 \pm 0.01 \mathrm{mmol} / \mathrm{l}, \mathrm{Cu}-\mathrm{PIII}: 0.25 \pm$ $0.02 \mathrm{mmol} / \mathrm{l})$.

The surface roughness did not reveal a significant influence on the $\mathrm{Cu}$ release in double-distilled water (Figure 2). Polished surfaces resulted in a $\mathrm{Cu}$ concentration in the supernatant of $0.23 \pm 0.01 \mathrm{mmol} / \mathrm{l}$. For the HA and corundum-blasted surfaces the $\mathrm{Cu}$ concentration is in the same dimension at $0.16 \pm 0.01 \mathrm{mmol} / \mathrm{l}$ and $0.20 \pm$ $0.01 \mathrm{mmol} / \mathrm{l}$, respectively. In comparison to DMEM, the $\mathrm{Cu}$ concentrations were significantly lower $(P \leq 0.007)$ for all 


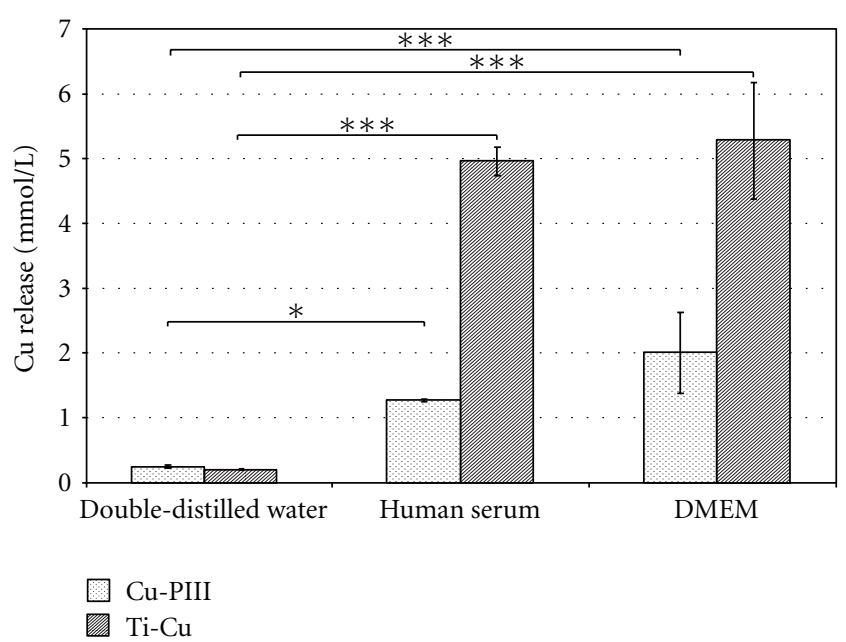

Figure 1: Copper concentration of Cu-PIII- and Ti-Cu-coated corundum-blasted Ti6Al4V surfaces submersed in $700 \mu \mathrm{L}$ of different supernatants (human serum, double-distilled water, and DMEM) for $24 \mathrm{~h}$ at $37^{\circ} \mathrm{C}$ and $5 \% \mathrm{CO}_{2}$; ANOVA (Post Hoc LSD) test, ${ }^{*} P<0.05,{ }^{* * *} P \leq 0.001$.

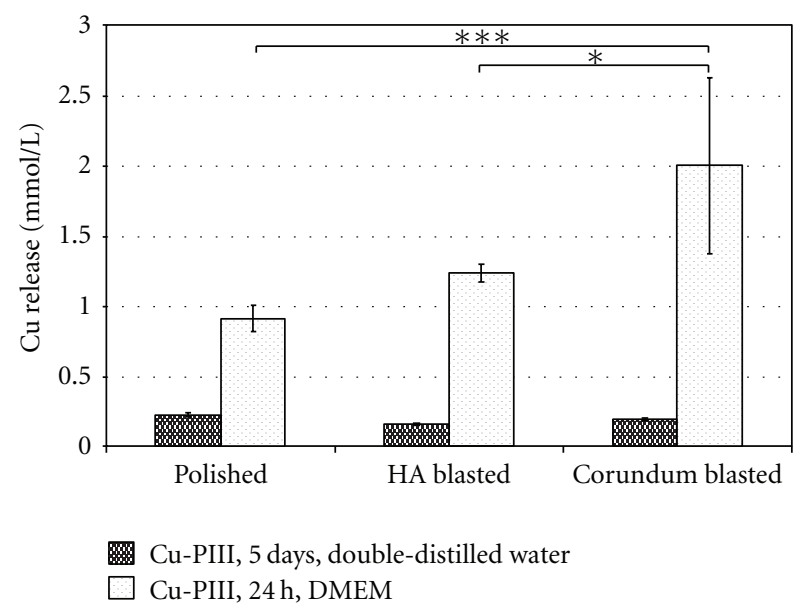

Figure 2: Copper concentration of Cu-PIII-treated Ti6Al4V samples with varying substrate surface roughness (polished, HA blasted, corundum blasted), submersed for 5 days in double-distilled water and $24 \mathrm{~h}$ in DMEM at $37^{\circ} \mathrm{C}$ and $5 \% \mathrm{CO}_{2}$. ANOVA (Post Hoc LSD) test, $* P<0.05, * * * P \leq 0.001$.

surface topologies using double-distilled water. Corundumblasted samples submersed in DMEM showed the highest $\mathrm{Cu}$ levels in the supernatant $(2.00 \pm 0.63 \mathrm{mmol} / \mathrm{l}, P \leq 0.004)$. A decrease in $\mathrm{Cu}$ concentration was observed for the polished samples in comparison to the HA-blasted $(P=0.156)$ and corundum-blasted $(P \leq 0.004)$ samples.

\section{Discussion}

In order to enhance implant survival, bioactive coatings have moved into the focus of research and development. Due to the increasing risk of implant infections from multiresistant bacteria such as MRSA (multiresistant Staphylococcus aureus)
$[10,11,23]$ or ESBL (enterobacteria producing extended spectrum beta-lactamases) [24], different antimicrobial coatings $[17,25-28]$ are being developed. However, the mechanical, biological and chemical properties of such innovative coatings have to be investigated thoroughly. $\mathrm{Cu}$ ions can be an effective antimicrobial agent to inhibit bacterial growth and biofilm formation on endoprosthetic surfaces $[10,29]$. Analyses of the ion release are strictly necessary for the determination of relevant $\mathrm{Cu}$ concentrations required in order to regulate both antimicrobial effects and compatibility to human cells. Furthermore, the release kinetics of copperdoped surfaces needs to be investigated in standardised tests in order to ensure effective and valid ion concentrations. In this context, however, standardised test conditions have not been established so far.

The AAS is a suitable device to measure $\mathrm{Cu}$ concentrations in supernatants. Uncoated samples did not show any $\mathrm{Cu}$ in any of the analysed supernatants, whereas the $\mathrm{Cu}$ treated samples revealed differences in $\mathrm{Cu}$ concentration. Nevertheless, using an AAS, both $\mathrm{Cu}^{+}$and $\mathrm{Cu}^{2+}$ ions are assessed at the same time without any distinction. However, only $\mathrm{Cu}^{2+}$ ions cause an antimicrobial effect [30]. Hence, the concentration alone is not enough to predict the effectiveness of the coating and should be supported by microbiological tests.

Investigations of the ion release of an antimicrobial coating should coincide with cell biological tests using human cells to study biocompatibility of the coating. Furthermore, test fluid volumes should be the same for all studies, ensuring similar $\mathrm{Cu}$ concentrations. A test fluid volume of $700 \mu \mathrm{L}$ was chosen to represent in vivo conditions. After conventional implantation technique, $\mathrm{Wu}$ et al. [31] observed that $40 \%$ of an uncemented femoral stem showed no bone contact with an average gap width between the bone and the femoral stem of $0.77 \mathrm{~mm}$. In relation to the test samples deployed in this study, a volume of approximately $200 \mu \mathrm{L}$ would be adequate to simulate the gap volume at the uncemented stem. However, $200 \mu \mathrm{L}$ is not enough to cover the test samples completely, which would make in vitro testing impossible. Therefore, a volume of $700 \mu \mathrm{L}$ was chosen as a compromise, which was the smallest possible volume that assured proper cell and bacterial growth in the supernatant.

The results of this study show that the amount of $\mathrm{Cu}$ ions released into the supernatant depends on various factors. The supernatant and its properties to dissolve $\mathrm{Cu}$ ions plays an important role. Surprisingly, the $\mathrm{Cu}$ concentration in double-distilled water for the Cu-PIII coating after 24 hours did not differ from the $\mathrm{Cu}$ concentration after 5 days. Therefore, double-distilled water showed an early $\mathrm{Cu}$ saturation for both tested coatings, whereas human serum and DMEM revealed a much higher $\mathrm{Cu}$ concentration in the supernatant. In fact, the highest concentration was obtained in DMEM for the Ti-Cu coating. The presence of serum proteins increases the solubility of $\mathrm{Cu}$ in the supernatants significantly compared to the double-distilled water because of the complex compounds between copper and amino groups found in the proteins in human serum and DMEM. Wu et al. [32] showed a higher concentration of $\mathrm{Ag}^{+}$ions after $24 \mathrm{~h}$ in cell culture medium as in simulated body 
fluid, which coincides with the $\mathrm{Cu}$ concentrations found in our present study. However, based on the current results, it is not possible to appoint a $\mathrm{Cu}$ ion saturation level for neither human serum nor DMEM. Repeated and cumulative investigations at different time periods need to be carried out and could provide a precise saturation level.

Surface roughness increases the surface area in contact with the supernatant. With rising surface roughness, an increase of the $\mathrm{Cu}$ concentration in the supernatant was observed. Compared to a polished surface, the corundumblasted surface released approximately three times as many $\mathrm{Cu}$ ions within $24 \mathrm{~h}$. In double-distilled water, the $\mathrm{Cu}$ concentration levels remained constant after 5 days regardless of the surface roughness, since the $\mathrm{Cu}$ saturation has set in within the first $24 \mathrm{~h}$.

Temperature may also influence the ion release characteristic of an implant material. Therefore, the release studies should be carried out at $37^{\circ} \mathrm{C}$ body temperature. A time-dependant $\mathrm{Cu}$ release behaviour, cumulative and non cumulative, of the analysed coatings is currently under investigation. First results show that most of the $\mathrm{Cu}$ is released during the first $24 \mathrm{~h}$, followed by a highly reduced release rate during the succeeding days. Furthermore, the effect of copper ions on human cells and tissue is currently under investigation provided by cell biological and microbiological tests as well as animal studies using an infection model.

\section{Conclusion}

When testing antimicrobial Cu-coated implant surfaces, it is important to apply appropriate test conditions regarding the ion release into the surrounding tissue. With respect to future clinical applications of the coated implants, a suitable test fluid such as human serum or DMEM should be used to coincide with cell biological and microbiological studies; otherwise, false conclusions may be drawn. Furthermore, it is important to use test samples with adequate surface properties close to those needed in the final application, since the surface roughness can affect the ion release dramatically.

\section{Acknowledgments}

This work was supported by the TEAM program of Mecklenburg-Vorpommern and the Helmholtz Association in Germany (UR 0402210, VH-MV1) and by the BMBF program Campus PlasmaMed (subproject PlasmaImp 13N9775, 13N11188). The authors thank Mr. U. Kellner, U. Lindemann (INP Greifswald), and L. Middelborg for the excellent technical assistance as well as Ms. A. Jonitz for the assistance in the statistical analysis.

\section{References}

[1] C. A. Jones, L. A. Beaupre, D. W. C. Johnston, and M. E. Suarez-Almazor, "Total joint arthroplasties: current concepts of patient outcomes after surgery," Rheumatic Disease Clinics of North America, vol. 33, no. 1, pp. 71-86, 2007.

[2] T. W. Bauer and J. Schils, "The pathology of total joint arthroplasty II. Mechanisms of implant failure," Skeletal Radiology, vol. 28, no. 9, pp. 483-497, 1999.
[3] W. Zimmerli, A. Trampuz, and P. E. Ochsner, "Current concepts: prosthetic-joint infections," New England Journal of Medicine, vol. 351, no. 16, pp. 1645-1654, 2004.

[4] A. Trampuz and W. Zimmerli, "Prosthetic joint infections: update in diagnosis and treatment," Swiss Medical Weekly, vol. 135, no. 17-18, pp. 243-251, 2005.

[5] D. Campoccia, L. Montanaro, P. Speziale, and C. R. Arciola, "Antibiotic-loaded biomaterials and the risks for the spread of antibiotic resistance following their prophylactic and therapeutic clinical use," Biomaterials, vol. 31, no. 25, pp. 63636377, 2010.

[6] A. Gristina, "Biomaterial-centered infection: microbial adhesion versus tissue integration. 1987," Clinical Orthopaedics and Related Research, no. 427, pp. 4-12, 2004.

[7] J. W. Costerton, P. S. Stewart, and E. P. Greenberg, "Bacterial biofilms: a common cause of persistent infections," Science, vol. 284, no. 5418, pp. 1318-1322, 1999.

[8] H. S. Ryu, I. H. Bae, and K. G. Lee, "Antibacterial effect of silver-platinumcoating for orthodontic appliances," Angle Orthodontist. In press.

[9] G. Borkow and J. Gabbay, "Copper as a biocidal tool," Current Medicinal Chemistry, vol. 12, no. 18, pp. 2163-2175, 2005.

[10] M. Haenle, A. Fritsche, C. Zietz et al., "An extended spectrum bactericidal titanium dioxide $\left(\mathrm{TiO}_{2}\right)$ coating for metallic implants: in vitro effectiveness against MRSA and mechanical properties," Journal of Materials Science: Materials in Medicine, vol. 22, no. 2, pp. 381-387, 2010.

[11] L. Weaver, J. O. Noyce, H. T. Michels, and C. W. Keevil, "Potential action of copper surfaces on meticillin-resistant Staphylococcus aureus," Journal of Applied Microbiology, vol. 109, no. 6, pp. 2200-2205, 2010.

[12] M. Yasuyuki, K. Kunihiro, S. Kurissery, N. Kanavillil, Y. Sato, and Y. Kikuchi, "Antibacterial properties of nine pure metals: a laboratory study using Staphylococcus aureus and Escherichia coli," Biofouling, vol. 26, no. 7, pp. 851-858, 2010.

[13] R. Sharan, S. Chhibber, and R. H. Reed, "A murine model to study the antibacterial effect of copper on infectivity of Salmonella enterica serovar Typhimurium," International Journal of Environmental Research and Public Health, vol. 8, no. 1, pp. 21-36, 2011.

[14] D. Neut, R. J.B. Dijkstra, J. I. Thompson, H. C. van der Mei, and H. J. Busscher, "Antibacterial efficacy of a new gentamicincoating for cementless prostheses compared to gentamicinloaded bone cement," Journal of Orthopaedic Research, vol. 29, no. 11, pp. 1654-1661, 2011.

[15] L. Wang, U. J. Erasquin, M. Zhao et al., "Stability, antimicrobial activity, and cytotoxicity of poly(amidoamine) dendrimers on titanium substrates," ACS Applied Materials \& Interfaces, vol. 3, no. 8, pp. 2885-2894, 2011.

[16] J. Holt, B. Hertzberg, P. Weinhold, W. Storm, M. Schoenfisch, and L. Dahners, "Decreasing bacterial colonization of external fixation pins through nitric oxide release coatings," Journal of Orthopaedic Trauma, vol. 25, no. 7, pp. 432-437, 2011.

[17] E. M. Hetrick and M. H. Schoenfisch, "Reducing implantrelated infections: active release strategies," Chemical Society Reviews, vol. 35, no. 9, pp. 780-789, 2006.

[18] S. Chandra, S. Raizada, M. Tyagi, and A. Gautam, "Synthesis, spectroscopic, and antimicrobial studies on bivalent nickel and copper complexes of bis(thiosemicrbazone)," Bioinorganic Chemistry and Applications, vol. 2007, Article ID 51483, 7 page, 2007.

[19] G. D. Christensen, L. Baldassarri, and W. A. Simpson, "Methods for studying microbial colonization of plastics," Methods in Enzymology, vol. 253, pp. 477-500, 1995. 
[20] K. Schröder, B. Finke, M. Polak et al., "Gas-discharge plasmaassisted functionalization of titanium implant surfaces," Materials Science Forum, vol. 638-642, pp. 700-705, 2010.

[21] V. Stranak, H. Wulff, H. Rebl et al., "Deposition of thin titanium-copper films with antimicrobial effect by advanced magnetron sputtering methods," Materials Science and Engineering $C$, vol. 31, no. 7, pp. 1512-1519, 2011.

[22] R. Marcus, E. Peritz, and K. R. Gabriel, "On closed testing procedures with special reference to ordered analysis of variance," Biometrika, vol. 63, no. 3, pp. 655-660, 1976.

[23] D. Ip, S. K. Yam, and C. K. Chen, "Implications of the changing pattern of bacterial infections following total joint replacements," Journal of Orthopaedic Surgery, vol. 13, no. 2, pp. 125-130, 2005.

[24] M. Haenle, A. Podbielski, M. Ellenrieder et al., "Periprosthetic infections following total hip replacement with ESBL-forming bacteria importance for clinical practice," Orthopade, vol. 40, no. 6, pp. 528-534, 2011.

[25] A. Ewald, S. K. Glückermann, R. Thull, and U. Gbureck, "Antimicrobial titanium/silver PVD coatings on titanium," BioMedical Engineering Online, vol. 5, article 22, 2006.

[26] G. Schmidmaier, M. Lucke, B. Wildemann, N. P. Haas, and M. Raschke, "Prophylaxis and treatment of implant-related infections by antibiotic-coated implants: a review," Injury, vol. 37, no. 2, pp. S105-S112, 2006.

[27] N. Y. Pfeufer, K. Hofmann-Peiker, M. Mühle, P. H. Warnke, M. C. Weigel, and M. Kleine, "Bioactive coating of titanium surfaces with recombinant human $\beta$-defensin-2 ( $\mathrm{rHu} \beta \mathrm{D} 2)$ may prevent bacterial colonization in orthopaedic surgery," Journal of Bone and Joint Surgery. Series A, vol. 93, no. 9, pp. 840-846, 2011.

[28] A. Fritsche, F. Heidenau, H. G. Neumann, W. Mittelmeier, and R. Bader, "Mechanical properties of anti-infectious, bioactive and wear resistant ceramic implant surface coatings," Key Engineering Materials, vol. 396-398, pp. 357-360, 2009.

[29] F. Heidenau, W. Mittelmeier, R. Detsch et al., "A novel antibacterial titania coating: metal ion toxicity and in vitro surface colonization," Journal of Materials Science: Materials in Medicine, vol. 16, no. 10, pp. 883-888, 2005.

[30] I. Iakovidis, I. Delimaris, and S. M. Piperakis, "Copper and its complexes in medicine: a biochemical approach," Molecular Biology International, vol. 2011, Article ID 594529, 13 pages, 2011.

[31] L. D. Wu, H. J. Hahne, and J. Hassenpflug, "The dimensional accuracy of preparation of femoral cavity in cementless total hip arthroplasty," Journal of Zhejiang University Science, vol. 5, no. 10, pp. 1270-1278, 2004.

[32] X. Wu, J. Li, L. Wang, D. Huang, Y. Zuo, and Y. Li, “The release properties of silver ions from $\mathrm{Ag}-\mathrm{nHA} / \mathrm{TiO}_{2} / \mathrm{PA} 66$ antimicrobial composite scaffolds," Biomedical Materials, vol. 5, no. 4, Article ID 044105, 2010. 


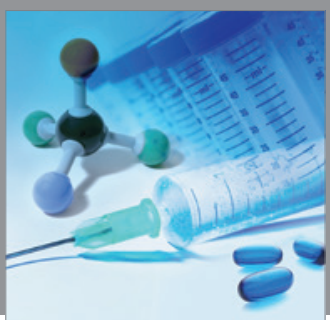

International Journal of

Medicinal Chemistry

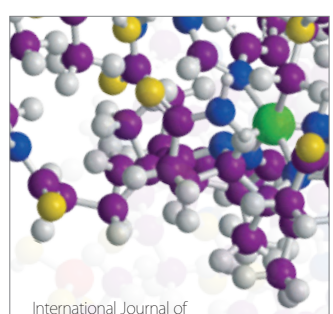

Carbohydrate Chemistry

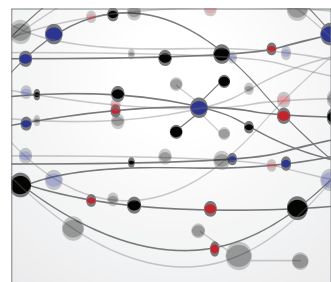

The Scientific World Journal
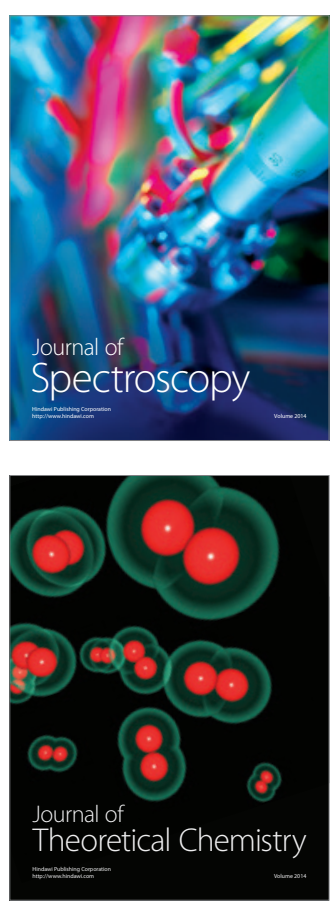
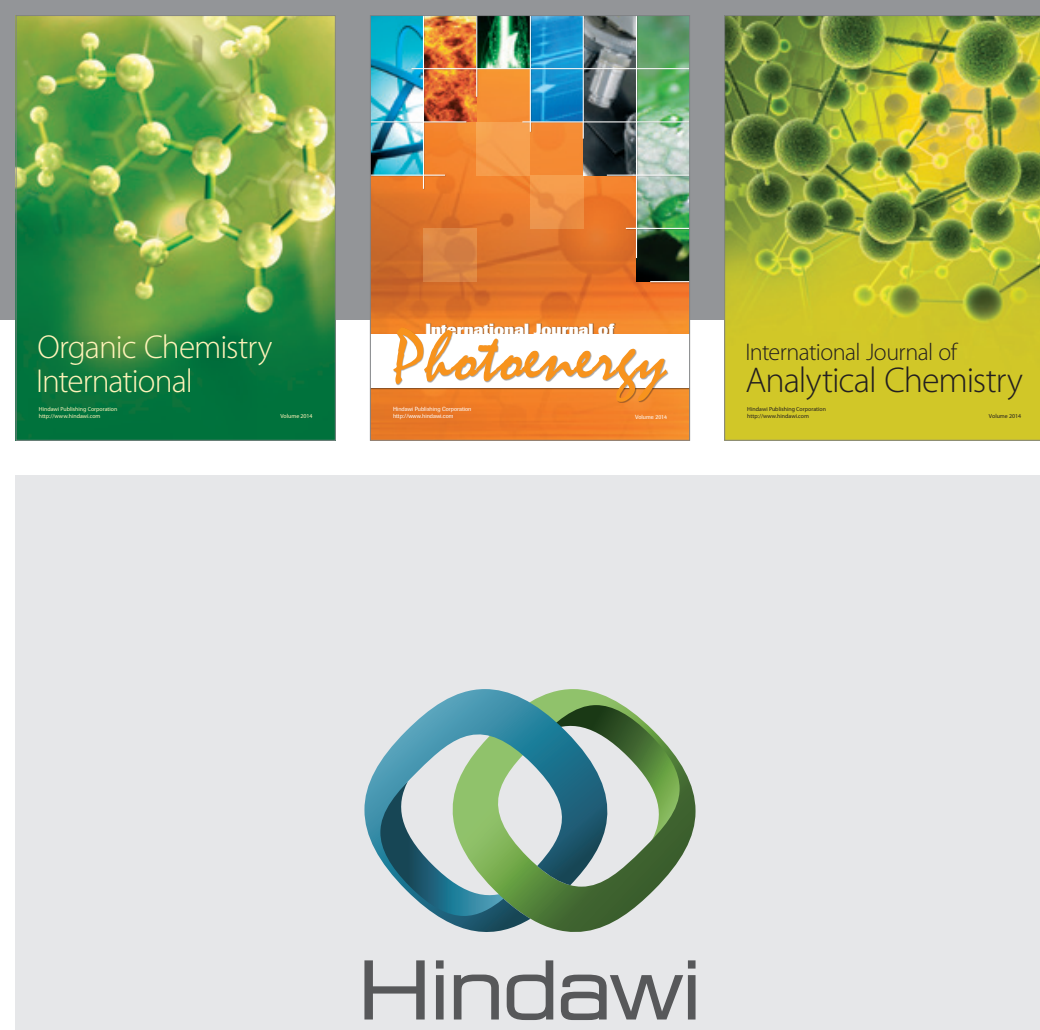

Submit your manuscripts at

http://www.hindawi.com
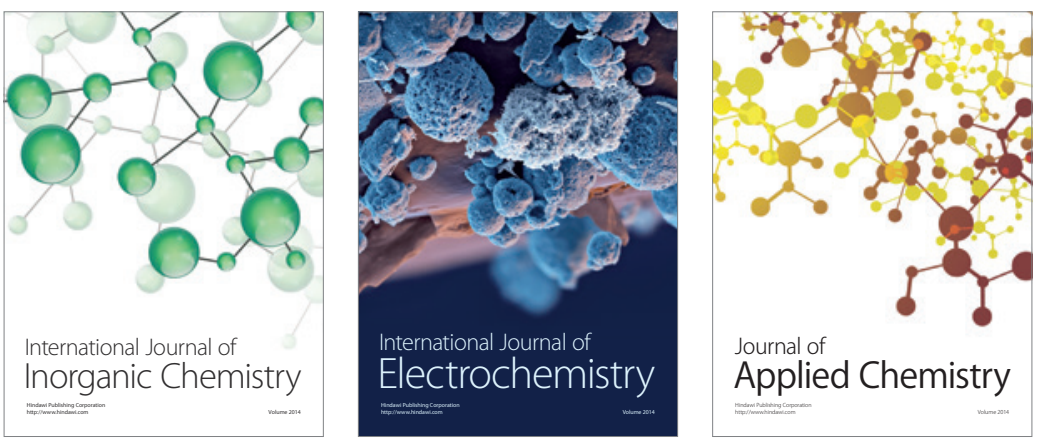

Journal of

Applied Chemistry
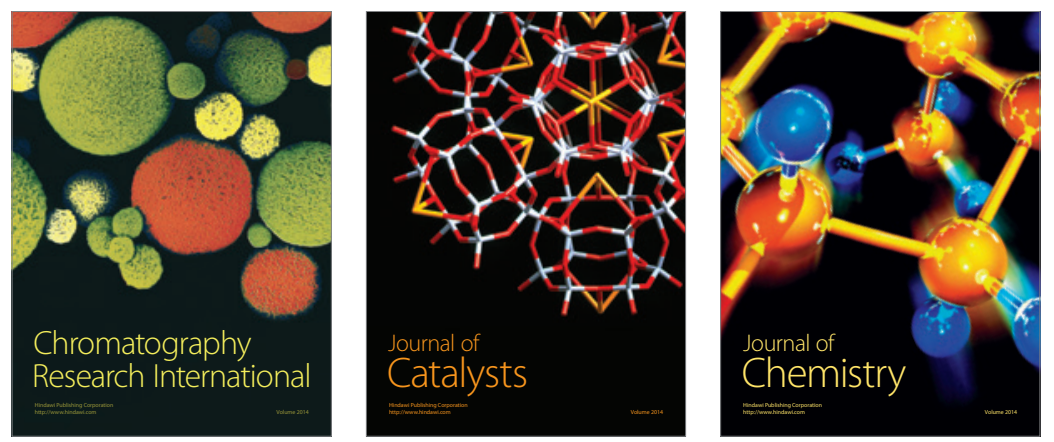
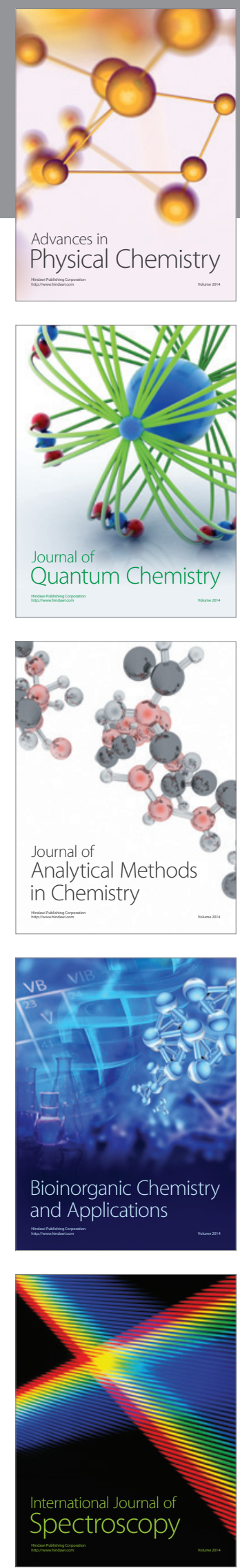